The Open Microbiology Journal
Bentham OPen
CrossMark
DOI: $10.2174 / 1874285801610010150$

REVIEW ARTICLE

\title{
A Systemic Review on Staphylococcal Scalded Skin Syndrome (SSSS): A Rare and Critical Disease of Neonates
}

\author{
Arun K. Mishra ${ }^{*}$, Pragya Yadav and Amrita Mishra \\ Central Facility of Instrumentation, Faculty of Pharmacy, IFTM University, Moradabad, UP, 244102, India
}

\begin{abstract}
The symptoms of Staphylococcal scalded skin syndrome (SSSS) include blistering of skin on superficial layers due to the exfoliative toxins released from Staphylococcus aureus. After the acute exfoliation of skin surface, erythematous cellulitis occurs. The SSSS may be confined to few blisters localized to the infection site and spread to severe exfoliation affecting complete body. The specific antibodies to exotoxins and increased clearence of exotoxins decrease the frequency of SSSS in adults. Immediate medication with parenteral anti-staphylococcal antibiotics is mandatory. Mostly, SSSS are resistant to penicillin. Penicillinase resistant synthetic penicillins such as Nafcillin or Oxacillin are prescribed as emergency treatment medicine. If Methicillin-resistant Staphylococcus aureus (MRSA) is suspected), antibiotics with MRSA coverage (e.g., Vancomycin or Linezolid) are indicated. Clindamycin is considered as drug of choice to stop the production of exotoxin from bacteria ribosome. The use of Ringer solution to to balance the fluid loss, followed by maintainence therapy with an objective to maintain the fluid loss from exfoliation of skin, application of Cotrimoxazole on topical surface are greatlly considered to treat the SSSS. The drugs that reduce renal function are avoided. Through this article, an attempt has been made to focus the source, etiology, mechanism, outbreaks, mechanism, clinical manisfestation, treatment and other detail of SSSS.
\end{abstract}

Keywords: Outbreaks, Pathophysiology, Staphylococcus aureus, Staphylococcal scalded skin syndrome (SSSS), Treatment.

\section{INTRODUCTION}

Staphylococcal scalded skin syndrome (SSSS) is counted as one of the major skin infections. In this infection, skin surface of large parts of body gets peeled off and looks like burned skin by hot liquid [1]. SSSS is also called as Ritter von Ritterschein disease, Ritter disease, Lyell disease and staphylococcal necrolysis of epidermis. The disease generally occurs in new borns, having remarkable blistering on superficial surface of skin caused by the exfoliative toxins released from Staphylococcus aureus [2, 3].

The symptoms of this disease include skin surface exfoliation followed by acute erythematous cellulitis [4]. Intensity of SSSS varies from a few watery blisters on some part of skin to a severe exfoliation affecting the entire body surface. These red blisters on skin surface looks like scaled or burned therefore, this infection has been termed as staphylococcal scalded skin syndrome [5]. Toxin producing strains of Staphylococcus aureus produce two exotoxins naming epidermolytic toxins A and B. These toxins form the basis of SSSS infection [6, 7]. Desmosomes (an integral part of skin) acts to adher the adjacent skin cell. The toxins from Staphylococcus aureus bind to molecule (Desmoglein 1) within the desmosome and get broken up in a manner so that skin cells loose adherence [8].

\section{S. aureus and Toxins}

Staphylococcus aureus is a gram (+) coccal bacterium and its occurrence is found near nose and nearby skin surface. The cases of pathogenecity of $S$. aureus is not observed everytime but even in some cases causes skin

\footnotetext{
* Address correspondence to this author at the Central Facility of Instrumentation, Faculty of Pharmacy, IFTM University, Moradabad, UP, 244102, India; Tel: +91-9451751810; Fax: +91-8923339467; E-mail: arun_azam@rediffmail.com
} 
infections such as blisters, lung infections and food poisioning etc. Few strains of this pathogenic bacterium often cause infections by releasing the toxins and with some surface proteins, which upon binding causes inactivation of antibodies. MRSA infection is caused by species of bacteria that are resistant to antibiotics being used to cure many ordinary infections. Strains of $S$. aureus secrete several exotoxins of three types [8, 9].

\section{Superantigens}

Superantigen induces syndrome disease like condition commonly known as toxic shock syndrome (TSS). TSS comprises of type B enterotoxin TSST-1 which causes TSS disease associated with tampon use. The symptom includes pyrexia, rashes on erythematous surface, hypotension like condition, multiple organ working failure, shock and desquamation of skin from epidermis etc. Absence of antibody against TSST-1 leads to pathogenesis of TSS [10]. S. aureus gastroenteritis is being caused by an enterotoxin produced from some strains of $S$. aureus. The bacteria induced gastroenteritis is self-limiting and identified by vomiting and diarrhea, with recovery time of 8 to $24 \mathrm{~h}$. Other symptoms of this gasteroenteritis include presence of nausea, vomiting, diarrhea and severe pain in lower abdomen $[11,12]$.

\section{Exfoliative toxin (EF)}

This kind of toxin is mostly observed in the case of infants and young children having Staphylococcal infection. The nurseries associated with hospitals may also posses EF. The released exfoliative toxins and their protease activity cause peeling off effect on skin surface [13].

\section{Other toxins}

Some other Staphylococcal toxins acting upon cell surface are alpha $(\alpha)$ toxins, beta $(\beta)$ toxin, delta $(\delta)$ toxin, and Panton-Valentine leukocidin (PVL). PVL toxin is related with intense necrotizing pneumonia specially in children [14, 15]. Recent study has revealed that PVL encoding conducted on bacteriophage occurring in community associated MRSA strains has opened new opportunity of further research.

\section{Carriers of $S$. aureus}

The carriage from nose contains strains of $S$. aureus in $35 \%$ of the population but this percentage may vary depending upon age and race. The patients of contact dermatitis, psoriasis and cutaneous T-cell lymphoma and atopic dermatitis are pronounced carrier of $S$. aureus. The outbreak of SSSS may be correlated with such carriers [16]. The occurrence of bacteria in neonates is very common especially on the skin, eyes, wound surface and umbilical stumps. The nursing homes and hospitals are counted as common sources of $S$. aureus, because of insufficient infection control practices, e.g. regular hand wash and cleaning stethoscopes between each patient. Newborns are at high risk of SSSS as bacteria are colonized within 6-days of birth. A study revealed that around $80 \%$ cases of SSSS occur in neonates, which are discharged from hospitals, especially in areas where the antiseptic umbilical cord care is discouraged. So far as the outbreak of SSSS is concerned, more bacterial colonization in neonates occurs from nursery attendants rather than mothers [17 - 19].

\section{RISK ASSOCIATED WITH SSSS}

Neonates and children of age group less than 5 years are generally at high risk of SSSS. In order to combat against SSSS, in childhood, body acquires lifelong immunity in form of antibodies against exotoxins of staphylococcal strain, which reduces the chance of SSSS in older children and adults [20]. Reduced immunity against bacterial exotoxins and imperfect renal clearance enhance the chance of SSSS in the neonates. The reason behind the fact includes that exotoxins are cleared through kidneys. It indicates that irrespective of age and sex, immunocompromised individuals and patients of renal failure are at risk of SSSS [21].

\section{SPREADING OF SSSS}

Infection arising from staphylococcal bacteria produces two types of toxins which include epidermolytic toxins A and B. An asymptomatic adult carrier of $S$. aureus transfers the bacterial strain into the neonates. Recent study has reported that about $15-40 \%$ of humans carry the $S$. aureus in their skin without any sign and symptom of infection [22, $23]$.

In neonates, the immune and renal systems are underdeveloped therefore; chance of occurrence of SSSS is more in neonates. Very rarely, SSSS infection occurs in adults, but the chances in immunocompromised and renal failure 
patients' cannot be ignored, as well as the patients taking the immune suppressant drugs or undergoing chemotherapy.

The staphylococcus bacteria are transferred from person to person by sharing towels or by droplets of coughing. Apart from this, persons who carry the bacteria but have no sign and symptom of infection can also transmit bacteria. Source of $S$. aureus is body organs including throat, ears and eyes [24, 25].

\section{SIGNS AND SYMPTOMS OF SSSS}

In general, starting symptom of SSSS includes fever and redness on entire surface the skin. Within 24-48 h, blisters with fluid accumulation are formed on the entire body. The blisters are ruptured and the resulting area appears as a burn. Large area of skin surface is peeled off or fall away showing the symptoms of exfoliation or desquamation.

In the SSSS, skin peeled off with gentle touch and leaves wet red areas appearing as burned skin (Nikolsky's sign) $[26,27]$.

\section{Symptoms on Skin}

In the area of groin, armpits, nose and ears, fluid accumulated blisters looking like tissue paper . The skin rashes spread rapidly into other legs and trunk. Diaper area of newborns is a very common place of skin rashes associated with SSSS. After $24 \mathrm{~h}$ of infection, the skin surface is peeled off in small sheets, leaving moist and reddish area on topical surface. Other symptoms of SSSS include intense pain around the infection site, weakness, fatigue and dehydration [28].

\section{IDENTIFICATION OF SSSS}

The appearance of skin itself clearly shows symptoms of SSSS. The oozed liquid or pus wrapped in cotton swab is used to identify the presence of the staphylococcal bacteria. Blood test is conducted in some cases to confirm the infection. Small skin piece is generally sent for microscopic examination [28].

In order to diagnose, the healthcare provider asks about the child's symptoms and medical history. The tests of skin biopsy and culture examination may also be performed to confirm the diasease condition.

\section{Biopsy of Skin sample}

Small skin sample is observed under the microscope.

\section{Culture test}

Culture test is performed to check the presence of specific bacteria. For culture, sample of blood, urine, nose, throat and skin are used. For neonates, culture of the umbilicus is done to diagnose SSSS [28, 29].

The main diagnostic features of SSSS are burn like epidermal exfoliation and damage of soft mucosa including oral mucosa and even in some cases vaginal mucosa. Few drugs have potential to cause toxic epidermal necrolysis (TEN). Irrespective of drug induced tissue necrolysis, in SSSS, there is necrolysis in all epidermal layers and prominent infiltration to the mucous membranes.

In the United Kingdom (UK), diagnosis of SSSS depends on clinical grounds, supported by the presence of S. aureus in nasal, conjunctival, pharyngeal, umbilical etc. but reliability of these parameters is still questionable [30]. In UK, the isolates are sent to the Public Health Laboratory (PHL), London, where the S. aureus would be phage typed. The presence of $S$. aureus in phage group II will strongly support the diagnosis of SSSS, even though other phage types show an identical clinical features [31]. For more confirmation, the PHL use immunological Ouchterlony method for toxins, which fails in sensitivity and specificity [32].

Serological gel immunoprecipitation, radioimmunological assays (RIA), enzyme linked immunosorbent assays (ELISA), gene sequence detection by DNA hybridization and polymerase chain reaction (PCR) are recently developed detection system for exfoliative toxins of SSSS [33]. False positive results might be observed in serological evaluation because of protein A (a $42 \mathrm{kDa}$ protein produced by over $90 \%$ of $S$. aureus), as it binds with constant (Fc) domain of immunoglobulins (IGs). The major drawback of these diagnostic techniques is that these are mean for laboratory-based research rather than clinical applications and the techniques are too costly and time consuming for routine analysis [34]. 


\section{DIFFERENTIAL FEATURES OF SSSS IN DIAGNOSIS}

1. Since past years, SSSS and TEN were assumed as same due to similarity in clinical characteristics. However, the pattern of skin peeling differs and TEN occurs due to drug reaction. However, using the skin biopsy can clearly differentiate between the two [35].

2. The exotoxin produces toxic shock syndrome and fever, which is called as Staphylococcal scarlet fever. This fever affects mainly children and the simple erythematous rash, without blisters or Nikolsky's sign, which is observed on days 5-10 followed by desquamation.

3. Pemphigus (group of autoimmune disorders having blistering of the skin and/or mucosal surfaces) differs from SSSS [36]. The word Pemphigus was used to include most bullous eruptions but better diagnostic tests intended for reclassification of bullous diseases. The bullae are superficial and confined to the epidermal layer. This is different to bullous pemphigoid in which bullae are on subepidermal surface. The major subclasses of the disorder are mentioned below with clinical characteristic and immunological attributes [37]:

i. Pemphigus vulgaris (PV): It is the very common and accounts for $70 \%$ of pemphigus cases.

ii. Pemphigus foliaceus (PF): The main charactestic feature of PF is the presence of skin lesions but this is directly related with antibodies to desmoglein 1 (DSG1).

iii. Others: This class includes Pemphigus herpetiformis, IgA pemphigus, paraneoplastic pemphigus and $\mathrm{IgG} / \mathrm{IgA}$ pemphigus and these forms are observed very rarely.

\section{INVESTIGATION}

The collected skin swabs are subjected to bacteriological confirmation and antibiotic sensitivities to identify the SSSS. The frozen skin biopsies of the lesions may be used to confirm the SSSS. In general, skin blisters give negative result in culture test, but $S$. aureus develops from some prominent site of infection as umbilicus, conjunctiva, breast, surgical wound, nasopharynx, blood. The patient and immediate relatives should be screened for asymptomatic nasal carriers of $S$. aureus [28].

The diagnosis of SSSS may be confirmed by the biopsy (taking a tissue sample of the infected area and microscopic examination of bacterial culture (by colonizing the collected sample to identify the causative organism).

\section{PATHOPHYSIOLOGY}

The skin is the largest organ in the human body containing five sublayers viz. Stratum corneum, Stratum lucidum, Stratum granulosum, Stratum spinosum, Stratum germinativum (Fig. 1). Below to the epidermis, a layer of dermis exists which is comprised of some tissues and acts to cushion the dermis from stress. Desmosome is a cell organelle responsible for adhesion among cells. Desmosomes are localized and spot-like structure but systemically arranged on the lateral end of cell membranes. The main action of desmosomes is to resist shearing forces and is found in simple and stratified squamous epithelium. In relation with SSSS, desmosomes are directly concerned [38, 39]. The desmosomes found in muscle tissue act to bind muscle cells to one another.

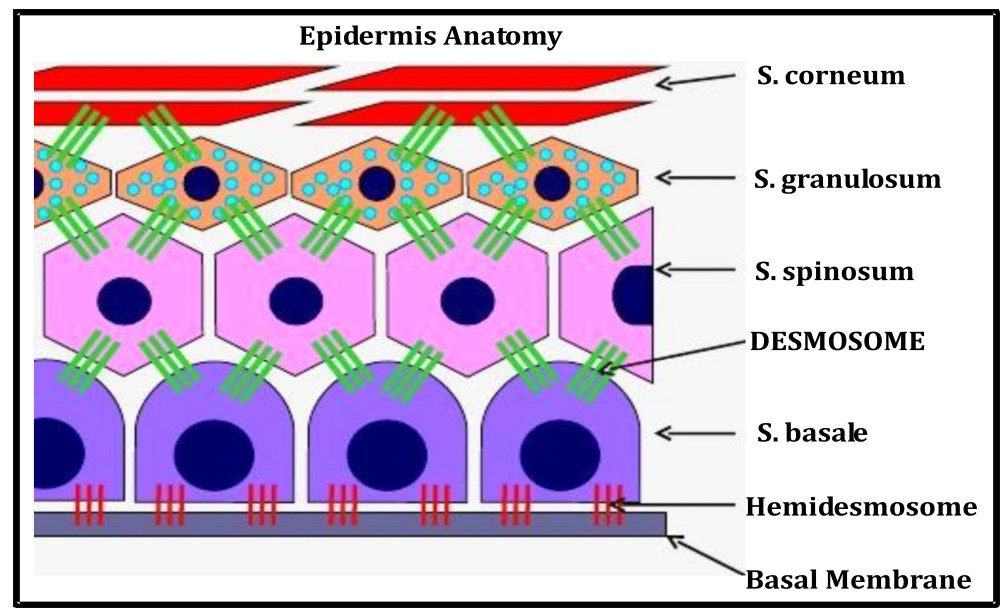

Fig. (1). Anatomy of skin epidermis. 
Exfoliative toxin A released from Staphylococcus aureus, causes blisters in skin surface and is known as staphylococcal scalded-skin syndrome. The toxin causes loss of cell adhesion in the epidermis. The skin damage is caused by release of epidermolytic toxins [40]. The released toxins are biochemically serine proteases and are circulated from a localized source, leaving epidermal erosion at distant sites (Fig. 2). It results into breakage of the desmoglobin 1, which acts as adhesion molecule, breaking up the skin by inhibiting the adhesion of skin cells. The detachment of superficial skin surface is the main symptom of SSSS. The exfoliative toxin attacks on Desmoglobin, which is responsible for cell-cell sticking leading to superficial lesion [41, 42].

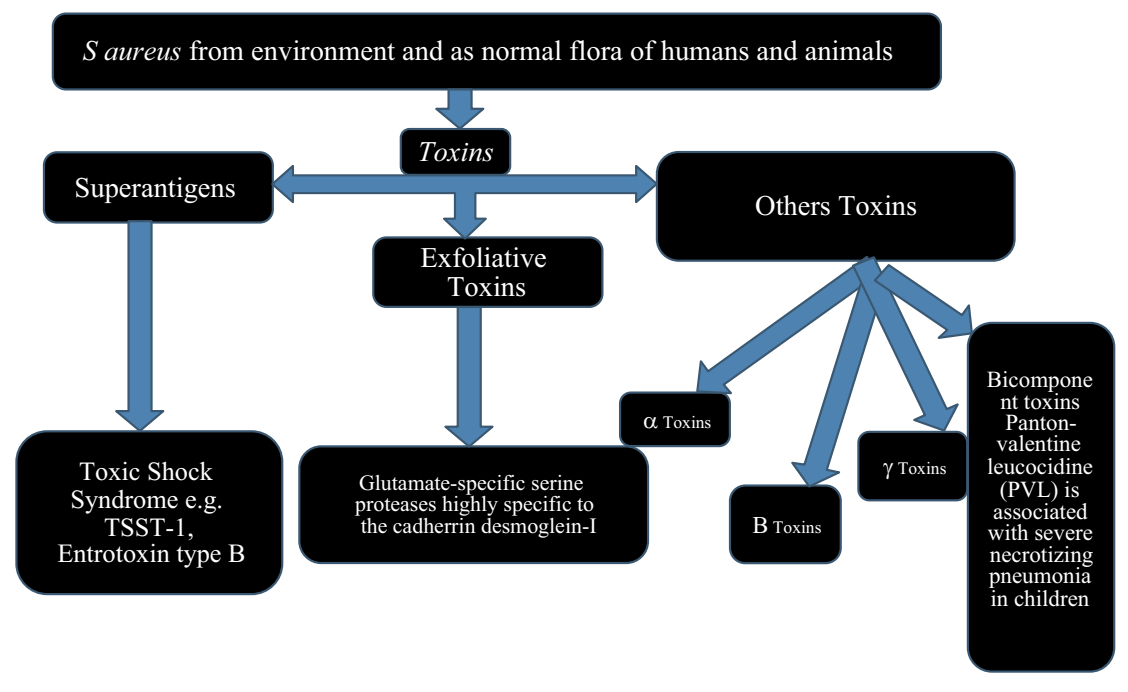

Fig. (2). Pathophysiology of SSSS.

\section{TREATMENT OF SSSS}

Supportive nursing care and focus to provide the fluid and electrolyte results in quick recovery from SSSS. Hospitalization is required to treat SSSS because antibiotics through intravenous route (i.v.) are necessary for absolute recovery from SSSS. Flucloxacillin (a penicillinase resistant, anti-staphylococcal antibiotic) is used sometimes. Oral antibiotics are also used after few days of treatment to replace antibiotics of $i . v$. route. In general, the patient of SSSS gets discharged from hospital with 6-7 days but advised to continue treatment afterwards, may be upto 15 days. Moist and ruptured skin surface require a layer of bland emollient to reduce tenderness. Paracetamol is usually first line drug to treat fever and pain associated with SSSS. It is given when necessary. Skin surface requires intense care as the skin is very fragile in SSSS patient. Topically, the therapy including either Fusidic acid or Mupirocin is applied as these drugs have proven cases of bacterial resistance $[43,44]$. Intravenous immunoglobulin had also been recommended to combat Staphylococcal scalded skin syndrome, but a recent study associates its use with prolonged hospitalization [45]. In a case reported in 2015, they used a double antibiotic therapy combining ceftriaxone and aminoside and also added important rehydration, antipain, and skin care with eosin liquid of $1 \%$ [46].

After start of blistering on skin surface in SSSS, initial $48 \mathrm{~h}$ are treated as critical but afterwards the disease is not considered as contagious keeping in view the fact that the appropriate antibiotics have been administered. The antibiotic treatment generally last in 7-10 d but some cases of MRSA require longer treatment depending on the intensity and spectrum of infection [47].

The children recover well from SSSS but the left outward signs of SSSS appear bad and healing of skin lesions completes within 5-7 days of initial treatment.

\section{OUTBREAKS OF SSSS}

The SSSS is not a very common disease throughout world. The first noticed outbreak of SSSS was in Ireland. In available literatures related with SSSS, a small number of outbreaks have been observed [48]. However, infections associated with $S$. aureus are increasing. From maternity and neonatal perspective, the staphylococcus infection (both methicillin-sensitive and resistant) is a matter of concern.

In one recent study, a massive outbreak of the SSSS with an unusual phage pattern was recorded during a 115-day 
period and study involved 68 neonates. The exfoliative dermatitis was observed in 24 neonates, and bacterial strains were isolated from 23 neonates. Eight babies had generalized staphylococcal scarlet fever [49]. Therefore, chance of outbreaks may not be neglected and especially in neonatal sections, it may be difficult to control. In case of outbreak of SSSS, either in neonatal care unit or at children caring centre, the possibility of a staphylococcal carrier in the nearby area should be screened. In order to manage the problem associated with outbreak of SSSS, the healthcare personnel, nursing care staff or visitors or infected persons with $S$ aureus should be identified. Upon identification of such persons, appropriate eradication medicines are to be given $[48,49]$. To avoid any further infections, the concerned should follow strict hand washing with antibacterial soap [50].

\section{COMPLICATIONS ASSOCIATED WITH SSSS}

The danger of SSSS lies in the fact that a different type of bacteria may invade some areas of the skin and may culminate complicated blood stream infection [51]. Loss of body fluid occurs when skin peels away, and the residual layer dries out; fluid loss is a critical issue at this time. As always, good hygiene can prevent the bacteria. In case of an outbreak, the nasal smears of neonates and staff associated should be examined. Improperly treated infections get worse. In SSSS, continous loss of fluid causing dehydration may worse the condition. Other complications include poor temperature control in young infants, septicemia (blood stream infection), Hair follicle infections including Staphylococcal folliculitis, boils, dermatitis, scabies, diabetic ulcers [52, 53].

\section{Cellulitis}

It occurs upon spreading of infection to a deeper layer of skin. It produces symptoms including reddish and inflamed skin with pain. The situation can usually be corrected with antibiotics and analgesics to reduce the pain.

\section{Guttate psoriasis}

In this, skin is noninfectious which may develop in teenagers after a bacterial infection but it occurs after a generalized throat infection. In this psoriasis, small, red, droplet-shaped, scaly patches are observed on the chest, arms and scalp. Antibacterial creams are applied on topical surface to control the symptoms and in some cases; the condition gets better even after 6-7 days.

\section{Septicaemia}

Septicaemia is a kind of bacterial infection of the blood. It causes diarrhea, cold, clammy skin, fever, vomiting, hypotension, confusion, faint feeling, dizziness and loss of consciousness [54].

\section{Scarring}

In rare cases, impetigo turns to scars. Scarring is considered as result of scratching at blisters, or sores. In general, the blisters and crusts do not leave a scar if left to be healed. The mark produced due to blisters disappears. The redness gradually diminishes varying from few days to few weeks.

\section{Post-streptococcal glomerulonephritis (PSG)}

It is an infection associated with small blood vessels in the kidneys. The symptoms of PSG are reddish-brown color of urine, abdominal swelling (tummy) and ankles, hematourea, reduced amount of urine. Patients suffering from PSG require immediate medical treatment and their blood pressure should be monitored carefully. PSG can be fatal in adults, but the cases of children are very rare.

\section{PREVENTION OF SSSS}

In order to prevent SSSS, several facts are to be considered which includes following points [55]:

i. Antibacterial/ antiseptic soap are to be used in hand wash.

ii. Clean towel or fresh clothing are to be used to dry the body or hands.

iii. The linens and clothes are to be washed in hot water.

iv. Antibacterial products are to be used in cleaning wall.

v. The fingernails must be short to avoid any contamination.

vi. Schools and childcare centers are to be avoided when the infection is in contagious form. 
vii. The personal hygiene items should not be shared.

viii. Washing hands before touching any damaged or broken skin.

ix. In cases of mild infections, bacterial colonizing can be prevented in the nostril and under the fingernails with antibiotic creams like Fusidic Acid or by using petroleum jelly several times daily, for a week of each month.

\section{FUTURE PRESPECTIVE IN SSSS}

Progress in our understanding of SSSS is improving at an exciting end. The toxins for the exfoliation in SSSS have been identified, characterized and their structure elucidated. More recently, the epidermal target has been identified and this has explored an exciting avenue for further research [56, 57]. Particularly, by analyzing the 3D structure of the complex of exfoliative toxins desmoglein-1, structural biologists should be able to confirm their speculated mode of action. Recently, research on SSSS involved injecting exfoliative toxin into live new born animals. At present, this process can be repeated in the lab by the toxin incubation with desmoglein-1 and measuring degradation of the latter. This type of simple and quick assay can be used to compare difference in properties of the various toxin serotypes. In particular, it may explain how ETC and S. hyicus exfoliative toxin A are able to induce exfoliation without conserving the serine-histidine-aspartate active site. In addition, site-directed mutagenesis can be used to produce mutant toxins to understand the properties of the toxins, such as their species specificity and their unique enzymatic and superantigenic activities. Differences in the amino acid sequence or the 3D structure of desmoglein-1could explain the species specificity of the different toxin serotypes, while desmoglein-1polymorphism may explain why only a small proportion of individuals who are exposed to exfoliative toxins develop the disease.

The possibility of new avenue in the field of SSSS include investigation and application of rapid, specific and sensitive diagnostic tests using desmoglein-1 as antigen for quantification of toxin in plasma or other biological fluids taken from suspected persons of SSSS. The future prospect includes synthesis of analoges of the toxin-binding regions of desmoglein-1 to inhibit the toxins and therefore, prevent exfoliation, in the similar pattern as it has been shown with L. monocytogenes, whose ability to invade epithelial cells and it can be inhibited by N-terminal fragments and recombinant proteins of E cadherin (CDH-1 gene) [58]. Most of the pediatric cases of SSSS get well with antibiotics and supportive care, treatment with desmoglein-lanalogues could be used for high risk cases such as adults with underlying diseases, children with extensive disease and immunocompromised patients. Such treatment may also be life saving in cases due to multidrug resistant $S$. aureus, where antibiotic treatment itself is not sufficient. A better understanding of the mechanism of action of the exfoliative toxins should also culminate to develop wide and more exciting applications. The better understanding of mechanism may be used by dermatologists to induce localised exfoliation to remove superficial skin lesions. Additionally, the binding site of desmoglein-1 of the toxins could be used to stabilise. This may protect the protein from destruction. Similarly, the targeting domain of the toxins which gives them such a specific site of action could be used to deliver drugs, such as chemotherapy, to a localized region within the epidermis. Another area that requires further research involves identification of factors that lead to development of the disease. In general, 1/3 population carries $S$. aureus commensally and out of total bacterial percentage, around $5 \%$ of these strains produce exfoliative toxin but only small proportion develop SSSS and generalized exfoliation. It is also possible that a triggering factor in either the organism or the host may be needed to produce the toxin, or the bacterial strain may continuously producing the toxins but the toxins would be prevented from reaching the epidermis, either locally on skin surface or in the blood.

The toxins released from bacterial strain crosss the mucous layer and endothelium of blood vessels. The mechanism of this fact needs to be investigated. Researchers have studied about the staphylococcal toxic shock syndrome toxin-1and enterotoxins A and B which is essential for crossing the gut layer. A synthetic peptide based has also been identified which is able to significantly reduce transcytosis [59]. The exfoliative toxins may serve as target for development of vaccines in future to eradicate SSSS.

\section{CONCLUSION}

SSSS is a critical syndrome in which acute exfoliation of the skin occurs followed by erythematous cellulitis. The main causative agent behind the fact is exfoliative toxins of S. aureus. Most of the cases of SSSS are cured absolutelly, specially when treatment starts in a very early stage of disease. Upon complete cure, Any visible difference or lasting marks to the skin surface does not appear. SSSS is treated with oral antibiotics (may be given by i.v. in severe cases). The area of skin surface requires cleansing and dressings with antiseptic cream. Emergency medical treatment is required in condition of imbalance fluid or salt. 


\section{CONFLICT OF INTEREST}

The authors confirm that this article content has no conflict of interest.

\section{ACKNOWLEDGEMENTS}

Authors would like to express sincere gratitude towards Dr. R. M. Dubey, Vice Chancellor, IFTM University, Moradabad for providing necessary help for the treatment of SSSS to Ms Arunima and ultimate library facility in the University for literature survey.

\section{REFERENCES}

[1] Itani O, Crump R, Mimouni F, et al. Picture of the month: SSSS. Am J Dis Child 1992; 146: 425-6. [PMID: 1558075]

[2] Conway DG, Lyon RF, Heiner JD. A desquamating rash; staphylococcal scalded skin syndrome. Ann Emerg Med 2013; 61(1): 118-119, 129. [http://dx.doi.org/10.1016/j.annemergmed.2012.05.025] [PMID: 23260687]

[3] Hubiche T, Bes M, Roudiere L, Langlaude F, Etienne J, Del Giudice P. Mild staphylococcal scalded skin syndrome: an underdiagnosed clinical disorder. Br J Dermatol 2012; 166(1): 213-5

[http://dx.doi.org/10.1111/j.1365-2133.2011.10515.x] [PMID: 21729032]

[4] Sah P, Rijal KR, Shakya B, Tiwari BR, Ghimire P. Nasal carriage Rate of Staphylococcus aureus in hospital personnel of National Medical College and Teaching Hospital and their susceptibility pattern. J Health Appl Sci 2013; 3: 21-3.

[5] Farroha A, Frew Q, Jabir S, Dziewulski P. Staphylococcal scalded skin syndrome due to burn wound infection. Ann Burns Fire Disasters 2012; 25(3): 140-2.

[PMID: 23467312]

[6] Hanakawa Y, Stanley JR. Mechanisms of blister formation by staphylococcal toxins. J Biochem 2004; $136(6)$ : 747-50. [http://dx.doi.org/10.1093/jb/mvh182] [PMID: 15671483]

[7] Ladhani S. Understanding the mechanism of action of the exfoliative toxins of Staphylococcus aureus. FEMS Immunol Med Microbiol 2003; 39(2): 181-9. [http://dx.doi.org/10.1016/S0928-8244(03)00225-6] [PMID: 14625102]

[8] Hubiche T, Bes M, Roudiere L, Langlaude F, Etienne J, Del Giudice P. Mild staphylococcal scalded skin syndrome: an underdiagnosed clinical disorder. Br J Dermatol 2012; 166(1): 213-5. [http://dx.doi.org/10.1111/j.1365-2133.2011.10515.x] [PMID: 21729032]

[9] Yamamoto T, Nishiyama A, Takano T, et al. Community-acquired methicillin-resistant Staphylococcus aureus: community transmission, pathogenesis, and drug resistance. J Infect Chemother 2010; 16(4): 225-54. [http://dx.doi.org/10.1007/s10156-010-0045-9] [PMID: 20336341]

[10] Acharya KR, Passalacqua EF, Jones EY, et al. Structural basis of superantigen action inferred from crystal structure of toxic-shock syndrome toxin-1. Nature 1994; 367(6458): 94-7. [http://dx.doi.org/10.1038/367094a0] [PMID: 8107781]

[11] Alouf JE, Müller-Alouf H. Staphylococcal and streptococcal superantigens: molecular, biological and clinical aspects. Int J Med Microbiol 2003; 292(7-8): 429-40. [http://dx.doi.org/10.1078/1438-4221-00232] [PMID: 12635926]

[12] Adesiyun AA, Lenz W, Schaal KP. Exfoliative toxin production by Staphylococcus aureus strains isolated from animals and human beings in Nigeria. Microbiologica 1991; 14(4): 357-62.

[PMID: 1775093]

[13] Wiedemann K, Schmid C, Hamm H, Wirbelauer J. Staphylococcal scalded skin syndrome in a very low birth weight premature infant. Z Geburtshilfe Neonatol 2016; 220(1): 35-8. [PMID: 26866691]

[14] Bhakdi S, Tranum-Jensen J. Alpha-toxin of Staphylococcus aureus. Microbiol Rev 1991; 55(4): $733-51$. [PMID: 1779933]

[15] Lina G, Piémont Y, Godail-Gamot F, et al. Involvement of panton-valentine leukocidin-producing Staphylococcus aureus in primary skin infections and pneumonia. Clin Infect Dis 1999; 29(5): 1128-32. [http://dx.doi.org/10.1086/313461] [PMID: 10524952]

[16] Kluytmans J, van Belkum A, Verbrugh H. Nasal carriage of Staphylococcus aureus: epidemiology, underlying mechanisms, and associated risks. Clin Microbiol Rev 1997; 10(3): 505-20. [PMID: 9227864]

[17] Koufakis T, Gabranis I, Karanikas K. Staphylococcal scalded skin syndrome in an adult, immunocompetent patient. Braz J Infect Dis 2015; 19(2): 228-9. [http://dx.doi.org/10.1016/j.bjid.2014.12.011] [PMID: 25701548] 
[18] Bitar CM, Mayhall CG, Lamb VA, Bradshaw TJ, Spadora AC, Dalton HP. Outbreak due to methicillin- and rifampin-resistant Staphylococcus aureus: epidemiology and eradication of the resistant strain from the hospital. Infect Control 1987; 8(1): 15-23. [http://dx.doi.org/10.1017/S0195941700066935] [PMID: 3643888]

[19] Jimenez-Truque N, Tedeschi S, Saye EJ, et al. Relationship between maternal and neonatal Staphylococcus aureus colonization. Pediatrics 2012; 129(5): e1252-9. [http://dx.doi.org/10.1542/peds.2011-2308] [PMID: 22473373]

[20] Aydin D, Alsbjørn B. Severe case of staphylococcal scalded skin syndrome in a 5-year-old child - case report. Clin Case Rep 2016; 4(4): 416-9. [http://dx.doi.org/10.1002/ccr3.535] [PMID: 27099742]

[21] Schwartz RA, McDonough PH, Lee BW. Toxic epidermal necrolysis: Part II. Prognosis, sequelae, diagnosis, differential diagnosis, prevention, and treatment. J Am Acad Dermatol 2013; 69(2): 187.e1-187.e16. [http://dx.doi.org/10.1016/j.jaad.2013.05.002] [PMID: 23866879]

[22] Arbuthnott JP, Kent J, Lyell A, et al. Studies of staphylococcal toxins in relation to toxic epidermal necrolysis (the scalded skin syndrome). Br J Derm 1972; 86: 35-9. [http://dx.doi.org/10.1111/j.1365-2133.1972.tb15412.x]

[23] Bailey CJ, de Azavedo J, Arbuthnott JP. A comparative study of two serotypes of epidermolytic toxin from Staphylococcus aureus. Biochim Biophys Acta 1980; 624(1): 111-20. [http://dx.doi.org/10.1016/0005-2795(80)90230-5] [PMID: 6773585]

[24] Bailey CJ, Lockhart BP, Redpath MB, Smith TP. The epidermolytic (exfoliative) toxins of Staphylococcus aureus. Med Microbiol Immunol (Berl) 1995; 184(2): 53-61. [http://dx.doi.org/10.1007/BF00221387] [PMID: 7500911]

[25] Cribier B, Piemont Y, Grosshans E. Staphylococcal scalded skin syndrome in adults. A clinical review illustrated with a new case. J Am Acad Dermatol 1994; 30(2 Pt 2): 319-24. [http://dx.doi.org/10.1016/S0190-9622(94)70032-X] [PMID: 8294590]

[26] Moss C, Gupta E. The Nikolsky sign in staphylococcal scalded skin syndrome. Arch Dis Child 1998; 79(3): $290-3$. [http://dx.doi.org/10.1136/adc.79.3.290] [PMID: 9875032]

[27] Oliveira AR, Aires S, Faria C, Santos E. Staphylococcal scalded skin syndrome. BMJ Case Rep 2013; 2013 : bcr2013009478. [http://dx.doi.org/10.1136/bcr-2013-009478]

[28] Handler MZ, Schwartz RA. Staphylococcal scalded skin syndrome: diagnosis and management in children and adults. J Eur Acad Dermatol Venereol 2014; 28(11): 1418-23.

[http://dx.doi.org/10.1111/jdv.12541] [PMID: 24841497]

[29] Machida K. Immunological investigations on pathogenesis of staphylococcal scalded skin syndrome. Rinsho Byori 1995; $43(6)$ : 547-56. [PMID: 7602798]

[30] Falk DK, King LE Jr. Criteria for the diagnosis of staphylococcal scalded skin syndrome in adults. Cutis 1983; 31(4): 421-4. [PMID: 6851638]

[31] Curran JP, Al-Salihi FL. Neonatal staphylococcal scalded skin syndrome: massive outbreak due to an unusual phage type. Pediatrics 1980; 66(2): 285-90.

[PMID: 6447271]

[32] de Azavedo JC, Arbuthnott JP. Assays for epidermolytic toxin of Staphylococcus aureus. Methods Enzymol 1988; $165: 333-8$. [http://dx.doi.org/10.1016/S0076-6879(88)65049-X] [PMID: 3148097]

[33] Mehrotra M, Wang G, Johnson WM. Multiplex PCR for detection of genes for Staphylococcus aureus enterotoxins, exfoliative toxins, toxic shock syndrome toxin 1, and methicillin resistance. J Clin Microbiol 2000; 38(3): 1032-5. [PMID: 10698991]

[34] Ladhani S, Evans RW. Staphylococcal scalded skin syndrome. Arch Dis Child 1998; 78(1): 85-8. [http://dx.doi.org/10.1136/adc.78.1.85] [PMID: 9534685]

[35] Perkin RM, Newton DA, Swift JD. Pediatric hospital medicine: Textbook of inpatient management. $2^{\text {nd }}$ ed. Philadelphia, PA: Lippincott Williams \& Wilkins 2008.

[36] Patel NN, Patel DN. Staphylococcal scalded skin syndrome. Am J Med 2010; 123(6): 505-7. [http://dx.doi.org/10.1016/j.amjmed.2009.09.041] [PMID: 20569752]

[37] Porro AM, Caetano LdeV, Maehara LdeS, Enokihara MM. Non-classical forms of pemphigus: pemphigus herpetiformis, IgA pemphigus, paraneoplastic pemphigus and IgG/IgA pemphigus. An Bras Dermatol 2014; 89(1): 96-106. [http://dx.doi.org/10.1590/abd1806-4841.20142459] [PMID: 24626654]

[38] Runswick SK, O’Hare MJ, Jones L, Streuli CH, Garrod DR. Desmosomal adhesion regulates epithelial morphogenesis and cell positioning. Nat Cell Biol 2001; 3(9): 823-30. [http://dx.doi.org/10.1038/ncb0901-823] [PMID: 11533662]

[39] Nishifuji K, Shimizu A, Ishiko A, Iwasaki T, Amagai M. Removal of amino-terminal extracellular domains of desmoglein 1 by 
staphylococcal exfoliative toxin is sufficient to initiate epidermal blister formation. J Dermatol Sci 2010; 59(3): 184-91. [http://dx.doi.org/10.1016/j.jdermsci.2010.07.010] [PMID: 20728315]

[40] Krieg T, Bickers DR, Miyachi Y. Therapy of skin diseases: A worldwide perspective on therapeutic approaches and their molecular basis. London, New York: Springer Heidelberg Dordrecht 2010. [http://dx.doi.org/10.1007/978-3-540-78814-0]

[41] Hanakawa Y, Schechter NM, Lin C, et al. Molecular mechanisms of blister formation in bullous impetigo and staphylococcal scalded skin syndrome. J Clin Invest 2002; 110(1): 53-60. [http://dx.doi.org/10.1172/JCI0215766] [PMID: 12093888]

[42] Amagai M, Matsuyoshi N, Wang ZH, Andl C, Stanley JR. Toxin in bullous impetigo and staphylococcal scalded-skin syndrome targets desmoglein 1. Nat Med 2000; 6(11): 1275-7. [http://dx.doi.org/10.1038/81385] [PMID: 11062541]

[43] Johnston GA. Treatment of bullous impetigo and the staphylococcal scalded skin syndrome in infants. Expert Rev Anti Infect Ther 2004; 2(3): $439-46$ [http://dx.doi.org/10.1586/14787210.2.3.439] [PMID: 15482208]

[44] Patel GK. Treatment of staphylococcal scalded skin syndrome. Expert Rev Anti Infect Ther 2004; $2(4): 575-87$. [http://dx.doi.org/10.1586/14787210.2.4.575] [PMID: 15482221]

[45] Handler MZ, Schwartz RA. Staphylococcal scalded skin syndrome: diagnosis and management in children and adults. J Eur Acad Dermatol Venereol 2014; 28(11): 1418-23. [http://dx.doi.org/10.1111/jdv.12541] [PMID: 24841497]

[46] Kouakou K, Dainguy ME, Kassi K. Staphylococcal Scalded Skin Syndrome in Neonate. Case Rep Dermatol Med. $2015 ; 4$.

[47] Stevens DL, Ma Y, Salmi DB, McIndoo E, Wallace RJ, Bryant AE. Impact of antibiotics on expression of virulence-associated exotoxin genes in methicillin-sensitive and methicillin-resistant Staphylococcus aureus. J Infect Dis 2007; 195(2): 202-11. [http://dx.doi.org/10.1086/510396] [PMID: 17191165]

[48] El Helali N, Carbonne A, Naas T, et al. Nosocomial outbreak of staphylococcal scalded skin syndrome in neonates: epidemiological investigation and control. J Hosp Infect 2005; 61(2): 130-8. [http://dx.doi.org/10.1016/j.jhin.2005.02.013] [PMID: 16009455]

[49] Curran JP, Al-Salihi FL. Neonatal staphylococcal scalded skin syndrome: massive outbreak due to an unusual phage type. Pediatrics 1980; 66(2): $285-90$.

[PMID: 6447271]

[50] Dancer SJ, Simmons NA, Poston SM, Noble WC. Outbreak of staphylococcal scalded skin syndrome among neonates. J Infect 1988; 16(1): 87-103. [http://dx.doi.org/10.1016/S0163-4453(88)96249-4] [PMID: 3367061]

[51] Lina G, Vandenesch F, Etienne J. Staphylococcal and streptococcal pediatric toxic syndrome from 1998 to 2000 . Arch Pediatr 2001; 8(Suppl. 4): $769 \mathrm{~s}-75 \mathrm{~s}$. [http://dx.doi.org/10.1016/S0929-693X(01)80195-0] [PMID: 11582926]

[52] Complications of impetigo. Available at: http://www.nhs.uk/Conditions/Impetigo/Pages/Complications.aspx [Accessed February 10, 2016].

[53] Hoffmann R, Lohner M, Böhm N, Schaefer HE, Leititis J. Staphylococcal scalded skin syndrome (SSSS) and consecutive septicaemia in a preterm infant. Pathol Res Pract 1994; 190(1): 77-81. [http://dx.doi.org/10.1016/S0344-0338(11)80499-1] [PMID: 8065992]

[54] Staphylococcal skin infections. Available at: http://www.dermnetnz.org/bacterial/staphylococci.html [Accessed February 10, 2016].

[55] Kapral FA. Staphylococcus aureus: some host-parasite interactions. Ann N Y Acad Sci 1974; 236(0): $267-76$. [http://dx.doi.org/10.1111/j.1749-6632.1974.tb41497.x] [PMID: 4278721]

[56] Ladhani S. Recent developments in staphylococcal scalded skin syndrome. Clin Microbiol Infect 2001; 7(6): 301-7. [http://dx.doi.org/10.1046/j.1198-743x.2001.00258.x] [PMID: 11442563]

[57] da Silva Tatley F, Aldwell FE, Dunbier AK, Guilford PJ. N-terminal E-cadherin peptides act as decoy receptors for Listeria monocytogenes. Infect Immun 2003; 71(3): 1580-3. [http://dx.doi.org/10.1128/IAI.71.3.1580-1583.2003] [PMID: 12595481]

[58] Lecuit M, Dramsi S, Gottardi C, Fedor-Chaiken M, Gumbiner B, Cossart P. A single amino acid in E-cadherin responsible for host specificity towards the human pathogen Listeria monocytogenes. EMBO J 1999; 18(14): 3956-63. [http://dx.doi.org/10.1093/emboj/18.14.3956] [PMID: 10406800]

[59] Shupp JW, Jett M, Pontzer CH. Identification of a transcytosis epitope on staphylococcal enterotoxins. Infect Immun 2002; 70(4): 2178-86. [http://dx.doi.org/10.1128/IAI.70.4.2178-2186.2002] [PMID: 11895985]

(C) Mishra et al.; Licensee Bentham Open

This is an open access article licensed under the terms of the Creative Commons Attribution-Non-Commercial 4.0 International Public License (CC BY-NC 4.0) (https://creativecommons.org/licenses/by-nc/4.0/legalcode), which permits unrestricted, non-commercial use, distribution and reproduction in any medium, provided the work is properly cited. 